\title{
PLANEJAMENTO EM PROMOÇAO EM SAÚDE UMA ABORDAGEM INTEGRADA
}

\author{
Nelly Martins Ferreira Candeias*
}

\begin{abstract}
CANDEIAS, N.M.F. Planejamento em promoção em saúde - uma abordagem integrada.
\end{abstract}
Rev.Esc.Enf.USP, v.30, n.1, p. 149-66, abr. 1996.

Este artigo refere-se ao problema específico do planejamento de programas de Promoção de Saúde e Educação, o qual envolve três níveis: o nível institucional, o nível programático e o nível dos usuários. Onde quer que tenha início o compromisso técnico, o ideal é organizar os três niveis, pois se assim não for o planejamento do programa será provavelmente acidental, fragmentado e ineficiente. Faz-se alguns comentários sobre a teoria de implementação, discutindo-se barreiras à implementação de programas em saúde e educação.

Unitermos: Planejamento. Programas de Promoção em Saúde e Educação. Nível institucional. Nível programático. Nível dos usuários. Teoria de implementação. Brasil.

\section{INTRODUÇÃO}

Este artigo tem como esquema de referência um paradigma organizacional fundamentado em três níveis de diagnóstico a realizar-se no sistema de atendimento médico-sanitário que se pretende analisar: nível institucional, nível programático e nível do usuário. O modelo prende-se à premissa que a educação em saúde dos usuários de serviços de atendimento (centros de saúde, ambulatórios, hospitais, outros) precisa ser planejada, coordenada e avaliada em relação àqueles três níveis, de forma complementar e integrada.

\footnotetext{
* Professor Adjunto do Departamento de Prática de Saúde Pública da Faculdade de Saúde Pública da Universidade de São Paulo.
} 
A publicação intitulada "A Model for Patient Education Programming" 15 descreve minuciosamente essa forma de diagnóstico, mostrando :que o processo de planejamento educativo exige,. em relação a cada uma das referidas dimensões, decisões fundamentadas em quatro diferentes processos: (a) levantamento dos recursos ' e das necessidades educativas; (b) planejamento das intervenções educativas; (C) implementação; e (d) avaliação.

Este modelo de planejamento tridimensional, que se subdivide nos itens referidos, tem-se mostrado instrumento útil de análise nos estágios de campo dos alunos do Curso de Especialização de Saúde Publica - opção Educação em Saúde, da Faculdade de Saúde Pública da Universidade de São Paulo. Nesse período, cabe aos alunos a responsabilidade de fazer um diagnóstico das atividades educativas dos programas de saúde de diferentes unidades de atendimento médico-sanitário. A orientação que então recebem é a de identificar as dificuldades sentidas em determinada unidade, no nivel institucional, no nivel programático, e no nível do usuário, mostrando como estas se refletem, respectivamente, nas atividades educativas ai desenvolvidas.

Até a presente data, parece-nos que nenhum artigo procurou analisar a prática da Educação em Saúde a partir deste paradigma tridimensional. Uma discussão desta natureza assume particular significado, entretanto, visto que a harmonia das atividades educativas depende 'inteiramente da integração equilibrada dos três níveis, observados aqui como um sistema.

Tendo em vista estas considerações, passa a ser objetivo do presente trabalho: (a) definir o processo de implementação; (b) descrever o modelo tridimensional e (C) apresentar exemplos práticos de implementação no nível institucional, no nível programático e no nível do usuário.

Para melhor compreensão do leitor, a Figura 1 ilustra este modelo de planejamento:

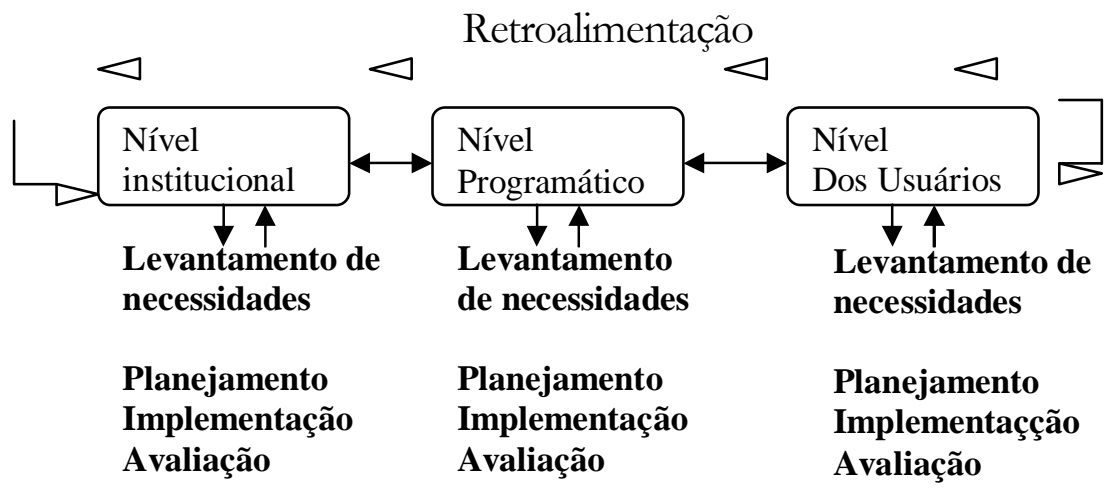

\section{FIGURA 1- ETAPAS SEQÜENCIAIS DE PLANEJAMENTO EDUCATIVO NAS TRÊS DIMENSÕES DO MODELO ORGANIZACIONAL}




\section{O PROCESSO DE IMPLEMENTAÇÃO}

OTTOSON: GREEN 21, no artigo intitulado "Reconciling Concept and Context: Theory of Implementation", fazem considerações que merecem ser aqui divulgadas. De acordo com estes autores, sendo as idéias e as ações entidades distintas, mudam necessariamente de forma (para não dizer, se acomodam) durante o processo de implementação. Como política de ação, as idéias emergem em geral junto ao governo central ou em núcleos de decisão Grganizacional, precisando ser implementadas em circunstâncias locais muito variadas. Como inovações, surgem em situações locais em que para promover inovações, tem-se que atingir setores mais conservadores. As idéias, como as teorias, têm origem em um tipo especifico de organização (por exemplo, Governo), porém são sempre implementadas em outros tipos de organização (por exemplo, serviços de saúde).

A problemática do confronto das idéias com atividades de rotina pode ser observada, atualmente, no processo de municipalização da saúde no Brasil, principal mecanismo para viabilizar os principios do Sistema Único de Saúde SUS. Essa proposta tem contribuído para identificar as insuficiências estruturais do paradigma anterior, cuja concepção era fundamentalmente centralizadora.

FASE A
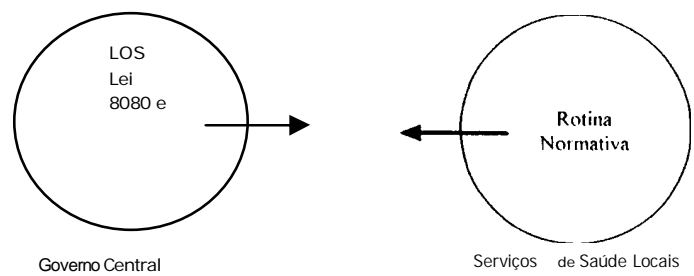

FASE B

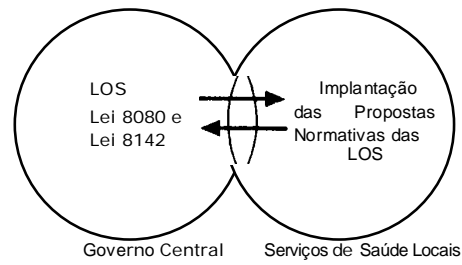

FIGURA 2 - INTERAÇÃO ENTRE IDÉIAS E IMPLEMENTAÇÃO 
O texto de OTTOSON E GREEN ${ }^{21}$ reflete claramente as dificuldades sentidas quando se pretende levar a teoria à prática. Em relação à municipalização da saúde, em nosso meio, muitos obstáculos têm-se levantado, opondo resquícios de um centralismo fortemente arraigado à manifestação de uma proposta centrada no conceito de cidadania organizada. Por um lado, encontram-se os "homens de idéias", tentando reorganizar a prática, com instrumentos técnico-científicos; por outro, encontram-se administradores interessados em racionalizar a prática o mais rapidamente possível. Há pois aqui um confronto conceitual entre os níveis intelectual e político. Como referem os autores, é preciso que o conceito e o contexto se alterem para que a implementação ocorra. A fidelidade total ao conceito significa que a idéia permanece virgem e, por isso, de pouco valor no campo. A total fidelidade ao contex to significa que não há nada para implementar.

Vejamos, a seguir, a definição operacional de implementação aqui compreendida como algo que diz respeito ao desenvolvimento de uma idéia em relação aos resultados de um programa.

1. A implementação é um processo e não um evento, ou seja, representa um conjunto de ações e não apenas uma ocorrência.

2. A implementação não é um processo isolado; é parte de um processo mais amplo de mudança. Durante a implementação, ambos, conceito e mudança se alteram. Tentar ajustar um à rigidez do outro é cooptação e não implementação.

3. A implementação tem aspectos relacionados a um início e a um fim. A política de ação precede à implementação e esta precisa fundamentar-se em um objetivo que permita avaliar o êxito da implementação.

4. A factibilidade precede à implementação. Se a política de ação for factível, também será implementável. É preciso que as decisões sejam realísticas em termos do nível local.

5. É necessário haver uma mútua adaptação entre a política de ação e o contexto, de forma que ambos fundamentem uma ação social.

6. A implementacão tem um foco próprio, além do foco da política de ação. A separação entre o delineamento do programa e a implementação é tão grave quanto o profissional de saúde ignorar se está realmente delineando ou implementando programas.

Esses são pontos fundamentais em termos da definição operacional de implementação, considerada como "um processo interativo no qual as idéias, expressas como política de ação, transformam-se em comportamentos expressos sob a forma de ação social" ${ }^{21}$. 


\section{O MODELO TRIDIMENSIONAL}

Resta perguntar sobre que pontos incide esse processo interativo, que denominamos de "implementação", na prática da saúde pública.

A interação entre conceito/idéia e política de ação/ação social incide sobre três diferentes níveis, como ilus tra o modelo tridimensional referido: o nível institucional, o nível programático e o nível do usuário. Portanto, ao se delinear a estratégia operacional de programas de Educação em Saúde, é preciso pensar em uma unidade constituída por idéia + contexto em cada uma dessas três dimensões. Para melhor compreensão do leitor e tendo em vista objetivos didáticos, descreveremos sucintamente esses três subsistemas.

\section{NÍVEL INSTITUCIONAL}

O nível institucional ou de sistema abrange dois aspectos significativos, um ao nível macro e o outro ao nível micro. Cabe-lhe executar as reformas propostas constitucionalmente pelo sistema de saúde e, ao mesmo tempo, planejar a infraestrutura necessária à implementação das atividades da unidade onde se realizam os serviços de saúde. É evidente que a política de saúde antecede à implementação programática no nível local, muito embora a realidade local fundamente sempre as mudanças propostas.

O Decreto $\mathrm{n}^{\circ} 94.657$, de 20 de julho de 1987 criou o Programa de Desenvolvimento de Sistemas Unificados e Descentralizados de Saúde (SUDS) nos estados da Federação, com o objetivo de contribuir para a consolidação e para o desenvolvimento qualitativo das Ações Integradas da Saúde. Nesse decreto explicita-se as atribuições dos três níveis federativos, contemplando a necessária redistribuição regional da renda no País, o que exige uma redefinição das competências da União, paralelamente a um processo de estadualização e, por meio deste, da municipalização das ações de saúde. A Constituição de 1988 devolveu aos municípios recursos que haviam sido historicamente descaracterizados durante o período autoritário, criando condições para a elaboração da Lei Orgânica do Município e tornando-o um poder autônomo no sistema federativo.

O nível institucional de planejamento assume um papel relevante exatamente em termos da revisão da organização dos serviços, expressa nas atuais políticas sociais e, mais especificamente, na política de municipalização. Isto porque os modelos de atenção à saúde passaram a considerar vários componentes, como a regionalização, a hierarquização, a integração de ações, a descentralização, a universalização e a participação popular. Na dimensão administrativa e em termos da Promoção em Saúde e da Educação, há, assim, formas organizativas com significados diferentes que incluem tanto o modelo de atenção centrado no indivíduo, enquadrando-se no modelo tradicional de 
educação clínica, quanto o modelo de atenção pautado na perspectiva do coletivo, incluindo-se aqui o modelo de educação voltado para a ação social.

A Lei $n^{\circ} 8.142$, de 28 de dezembro de 1990 foi editada tendo em vista os vetos que a Lei $\mathrm{n}^{\circ}$ 8.080/90 recebeu em relação à participação da comunidade (art.11) e ao repasse direto dos recursos (parágrafos $2^{\circ}$ e $3^{\circ}$ do artigo 33 e parágrafo $5^{\circ}$ do artigo 35). Esses artigos não deveriam ter sido vetados, pois enquanto um regulamentava a Constituição (artigo 198, III, da participação da comunidade), o outro buscava interpretar a intenção do legislador constitucional no sentido de descentralizar a execução das ações e dos serviços públicos de saúde, ao determinar a transferência de recursos da União para os Estados, DF e Municípios de forma direta, independentemente da celebração do instrumento jurídico ${ }^{14}$.

Com a Lei $\mathrm{n}^{\circ}$ 8.142/90 restabeleceu-se a participação comunitária na gestão do SUS por meio da criação dos Conselhos de Saúde e das Conferências da Saúde, disciplinando-se também a transferência dos recursos arrecadados pela União, para os Estados, para o DF e para os Municípios. Como ressaltam Carvalho e Santos 14, no conceito de controle social encontra-se a expressão mais significativa da participação da sociedade nas decisões tomadas pelo Estado. Quanto à saúde, o texto constitucional de 88 enuncia como uma das diretrizes do SUS, a participação da comunidade (artigo 194, VII), que se efetiva por meio da representação em órgãos colegiados deliberativos, fornecimento de subsídios às autoridades envolvidas na gestão dos serviços e ações de saúde e proposta ou reivindicação de medidas especificas destinadas a atender às necessidades da população.

A presença dos usuários nos Conselhos de Saúde (nacional, estadual e municipais), paritária em relação ao conjunto dos demais segmentos do colegiado, expressa uma conquista do SUS de impressionante alcance político ao colocar o Cidadão no centro do processo de avaliação das ações e dos serviços de saúde. Do ponto de vista prático, como alerta a definição operacional de implementação, é necessário haver mútua adaptação entre a política de ação e o contexto, de forma que ambos fundamentem uma ação social.

Apesar dos benefícios inerentes à execução das LOS, a sua implantação tem sido penos a, particularmente no que se refere à articulação entre gestores. No Seminário recentemente realizado pela Faculdade de Medicina da Universidade de São Paulo e pelo Fórum em Defesa da Saúde e da Vida, fezse referência à implantação de 20 CES e ao fato de os 20 Estados terem inicialmente se recusado a organizá-los, apesar da Lei ${ }^{\circ} 8.142$. Os Conselhos Estaduais de Saúde acabaram sendo estruturados porque o CNS, utilizandose da prerrogativa de estabelecer critérios para repasse de verba, informou que Estados sem CES não teriam acesso a auxílios financeiros. Muitos são os obstáculos a eliminar, tais como, conselhos com reduzida ou nenhuma participação da comunidade e melhor qualificação dos conselheiros, para que possam desempenhar suas funções como representantes legítimos do interesse coletivo $^{16}$. 
Trata-se portanto, já se disse, de aproximar as idéias do texto constitucional à implementação das atividades nos serviços de saúde, em um clima de cidadania organizada. (Figura 2)

Em termos da descentralização do modelo de prestação dos serviços, o planejamento a nível institucional deve considerar: as pessoas diretamente envolvidas nas decisões que afetam a política social e os usuários a quem os esforços se dirigem; a estrutura e as características específicas da instituição; as forças propulsoras propícias ao processo de municipalização no resgate da autonomia municipal; as debilidades e riscos que favoreçam a possibilidade de fragmentação. Esta pode ocorrer pela ausência ou fragilidade da explicitação do modelo assistencial em termos da organização dos serviços de gestão, em cada estado da Federação; pela vinculação insuficiente entre os municípios e o nível federal, pela ausência do controle social e pela desconsideração velada pelos mecanismos de participação. Nos termos do SUS, a população-alvo para quem os esforços se dirigem passa a ser constituída por pessoas com poder administrativo de decisão, como diretores, chefes de serviços, membros do Conselho de Saúde ${ }^{19}$, etc.

Além dessa incumbência de caráter macro-social, uma outra precisa ser também considerada. A instituição deve voltar-se para si própria, fazendo um diagnóstico administrativo da estrutura física da unidade, localização, financiamento, características dos serviços oferecidos, recursos específicos para ações educativas (pessoal, espaço, equipamento) e acesso a recursos de outras agências. Note-se que no nível institucional, seja no nível macro ou micro, as decisões administrativas não dizem respeito nem à estrutura técnica de programas educativos, nem à população-alvo que se procura atingir. Ambos se prendem aos outros dois níveis de planejamento do paradigma tridimensional.

As principais questões que caracterizam o diagnóstico institucional são: qual é a política de ação da unidade em relação aos pressupostos do Sistema Único de Saúde? Qual a postura administrativa quanto à implementação (conceito + contexto) das atividades educativas? Quais são os canais de comunicação e como se dá o intercâmbio entre a instituição e o Conselho de Saúde? Está-se realizando a articulação entre os gestores? Que tipos existem de coordenação intersetorial? Há gastos, recursos, pessoal, verbas, potencial e vontade política?

Fica claro que a avaliação nesse nível terá como objeto de interesse a observação dos alicerces da estrutura, tanto em termos da formulação de uma política de ação ajustada ao SUS, quanto em termos da alocação dos recursos financeiros e humanos dirigidos às necessidades do atendimento quotidiano dos usuários.

De acordo com DEEDS e colaboradores ${ }^{15}$, e com CANDEIAS ${ }^{12}$, a prática da Promoção em Saúde e da Educação tem se concentrado mais no 
delineamento e na avaliação de programas específicos, em geral desarticulados, do que na análise da política de ação e da própria estrutura organizacional da unidade de atendimento, onde se pretende implementar ações educativas. Equivale isto a pensar, ilogicamente, que o segmento subsistêmico não depende de sistema global. A nosso ver, esse desiquilíbrio representa talvez o mais grave paradoxo da prática educativa em nosso meio.

\section{NÍVEL PROGRAMÁTICO}

Se o nível institucional considera os alicerces do sistema global, no nível da política de ação do sistema de saúde (central) e no nível da infraestrutura necessária aos programas educativos de cada unidade (local), o nível programático ocorre na própria unidade onde se espera que o programa seja implantado, fazendo um diagnóstico da situação e procurando analisar as funções educativas em termos dos problemas de saúde em comum. O objetivo nesse nível é a qualidade técnica do programa; inclui-se aqui, portanto, o diagnóstico da situação de indivíduos e de grupos específicos, o planejamento do conteúdo, explicitando-se sempre os objetivos da aprendizagem (quem? o que? quanto? quando? onde?) e a seleção de estratégias de avaliação. Desta forma a população-alvo para quem os esforços se dirigem continua sendo constituída por pessoas com poder de decisão na unidade de atendimento, mais particularmente, diretores e os chefes dos serviços nos quais se pretende que as atividades sejam implementadas. O envolvimento da chefia em pontos críticos de decisão é fundamental para o êxito dos programas.

Nesse nível, a essência da análise prende-se à importância relativa de cada um dos problemas de saúde. É preciso verificar se os problemas considerados prioritários apresentam componentes comportamentais possíveis de intervenção educativa, uma vez que as mudanças comportamentais, sejam elas individuais ou coletivas, representam de fato o principal objetivo da Educação em Saúde como prática social.

As perguntas básicas para a avaliação, neste nível, são: o plano deu certo? Houve integração do plano no sistema da unidade? Houve documentação pertinente, horizontal e vertical na instituição? As pessoas estão satisfeitas com a implementação do programa? Conseguiu-se uma interação produtiva com as outras equipes da unidade? Houve envolvimento e participação dos representantes dos usuários no planejamento, implementação e avaliação das atividades programáticas?

\section{NÍVEL DE USUÁRIOS}

Vejamos, finalmente, algumas características do nível de usuários.

Os usuários representam o alvo terminal das atividades educativas a 
serem desenvolvidas. Como ocorre com o planejamento nos níveis institucional e programático, nesta dimensão torna-se necessário fazer um levantamento de necessidades, incluindo-se entre estas as necessidades dos próprios usuários, com eles próprios participando no processo educativo de implementação e avaliação do plano educativo 4,6,8

É nesse nivel, também, que se identificam os conhecimentos, atitudes, habilidades e práticas (CAHP) dos profissionais da saúde em relação à estrutura do programa educativo, assim como os conhecimentos, atitudes, habilidades e práticas dos usuários em relação à proposta de ensinoaprendizagem implícita naquele programa 2,5 As quatro perguntas que estruturam o modelo CAHP no planejamento de programas de ensino em saúde são: que sabe? que acha? o que faz? como faz?

A Figura 3 ilustra esta situação.
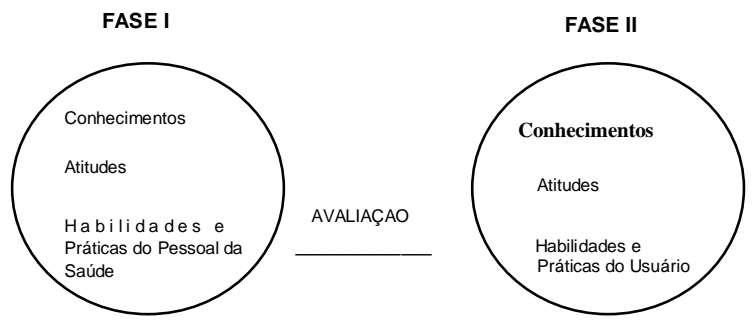

Objetivo I - Treinamento em serviço do pessoal da saúde em relação ao programa

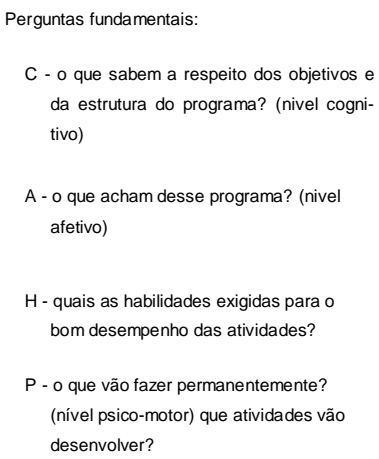

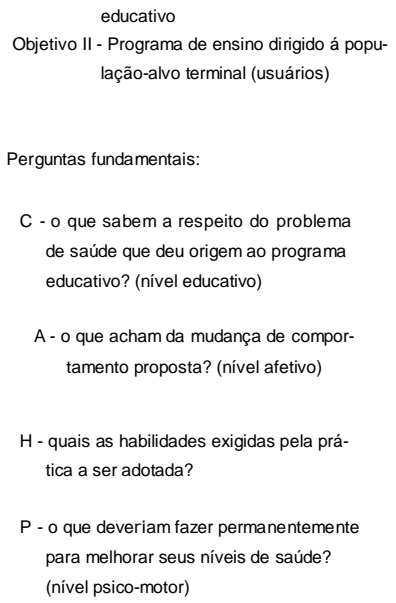

\section{FIGURA 3. FASES DO MODELO CAHP}


Como se observa na Figura 3, o modelo CAHP dirige-se não s6 à população-terminal (usuários), mas também à população-intermediária (pessoal da saúde) responsável pela implementação do programa educativo.

Muitos estudos evidenciam a defasagem entre o que se ensina, e em que circunstâncias, e o que o usuário deseja de fato aprender, mostrando, além disso, que nem sempre os próprios profissionais de saúde concordam com os objetivos do conteúdo educativo do processo ensino-aprendizagem.

Um modelo útil para a aplicação do CAHP dirigido aos usuários (Fase 2, Figura 3) é o Modelo de Crenças em Saúde. Este modelo sugere que a ação em saúde tem maior probabilidade de ser desencadeada quando os indivíduos (a) acreditam ser susceptíveis à doença e às suas conseqüências; (b) acreditam que se contraírem a doença sofrerão sérias conseqüências; (C) sabem o que fazer do ponto de vista preventivo e, finalmente, (d) acreditam ser maiores as vantagens da ação de saúde do que quaisquer outras desvantagens que possam acompanhá-la.

É no nível dos usuários, também, que se levantam as características sócio-demográficas da população-alvo, como idade, sexo e nível sócioeconômico, entre outros.

No Brasil, grande parte dos estudos concentra-se apenas nesse nível ${ }^{12}$, abordando em geram apenas os conhecimentos dos educandos. Poucos se interessam pelos aspectos relacionados às atitudes, habilidades e práticas dessa população, jamais considerando o planejamento organizacional nas três dimensões que, de forma integrada, deveria fundamentar o alicerce das atividades educativas dos programas de saúde.

Uma vez referido de forma sucinta o esquema que caracteriza essa abordagem para o planejamento de atividades educativas em programas de saúde, apresentaremos alguns exemplos da nossa experiência pessoal, mostrando como o despreparo conceitual prejudica ou, muitas vezes, impede totalmente o bom desempenho ou a implementação de programas educativos em cada um dos três níveis acima referidos.

\section{EXEMPLOS PRÁTICOS}

\section{NÍVEL INSTITUCIONAL}

Um estudo realizado em hospitais da Prefeitura de São Paulo teve como objetivo verificar a existência ou não de três variáveis essenciais ao desenvolvimento das atividades educativas dirigidas aos usuários de serviços de atendimento médico-sanitário - coordenação, consultoria e orçamento ${ }^{9}$. Os dados foram coletados mediante a aplicação de um questionário que, com algumas alterações, reproduziu um instrumento já utilizado nos Estados Unidos. ${ }^{1}$ 
Em relação à rotina dos hospitais, é prática corrente fornecer informações a pacientes e familiares sobre aspectos ligados à manutenção da saúde. No Brasil, entretanto, estas atividades não se fundamentam em níveis razoáveis de planejamento técnico, tornando impraticável a supervisão e a avaliação do processo educativo em seus vários níveis. Para responder às necessidades dos usuários e de seus familiares, na pré-admissão, admissão, internação, alta médica e, se for o caso, acompanhamento posterior, torna-se necessário planejar os objetivos e as atividades educativas nos níveis acima descritos: no nível institucional, ou seja, considerando a unidade como um todo; no nível programático, isto é, em termos da qualidade técnica dos programas dirigidos a grupos específicos e, "last but not least", no nível da população-alvo a quem se dirige o programa - usuários dos serviços e familiares.

É inegável que o nível institucional condiciona a qualidade técnica dos outros dois níveis. Apesar disso constatou-se que, dos seis hospitais em estudo, em cinco não havia um departamento responsável pela coordenação das atividades educativas. Dos seis hospitais, cinco não contavam sequer com um profissional responsável pela coordenação das atividades educativas. Além disso, nenhum dos seis hospitais tinha solicitado consultoria externa para colaborar no planejamento de programas de educação para seus usuários.

Apresenta-se, a seguir, por ordem decrescente de importância, os programas educativos para os quais, de acordo com as respostas, os hospitais da Prefeitura gostariam de receber consultoria.

Em 10 lugar: programas de saúde na comunidade local, recreação infantil, bronquites crônicas, planejamento familiar, diabetes, politraumatismo.

Em 20 lugar: papel da agência de saúde no tratamento, diabetes, doenças cardíacas, sexualidade, hipertensão, famílias participantes.

Em $3^{\circ}$ lugar: alcoolismo, cirrose, gestação de adolescentes, aleitamento materno, orientação para gestantes, orientação para puérperas.

Em $4^{\circ}$ lugar: queimaduras, psicopatia, diabetes, aleitamento materno, cuidados com o recém-nascido, orientação para diferentes níveis de tratamento.

Em $5^{\circ}$ lugar: ortopedia, paciente com câncer, hipertensão, psicoprofiláticos para gestantes, preparo e higiene de alimentos, pediatria.

Alem desses programas que representam as 5 primeiras prioridades mencionadas pelos inquiridos, outros foram também referidos: clínica cirúrgica, clínica médica, pediatria, educação materno-infantil, emergências, diabetes na gravidez, hipertensão na gravidez, aborto, câncer ginecológico, climatério, preparo para a cirurgia e problemas gastrointestinais em crianças. $E$ interessante observar que, com maior ou menor especificidade, 42 temas foram enumerados para efeito de consultoria nos hospitais da Prefeitura de São Paulo. 
Também verificou-se que, além de aspectos ligados à coordenação e à consultoria, nenhum dos seis hospitais contava com recursos financeiros para o desenvolvimento de atividades dessa natureza, tornando praticamente inviável qualquer esforço nesse sentido. É óbvio que sem coordenação, sem consultoria e sem recursos financeiros, torna-se praticamente impossível realizar programas educativos, a não ser de maneira falha e incompleta.

Um outro exemplo ilustra barreiras inerentes ao nível institucional, detectadas no Hospital Universitário, situado no campus da Universidade de São Paulo. Durante três meses fez-se uma observação técnica das atividades educativas em um dos Serviços desse Hospital. Nessa ocasião verificou-se que, apesar de haver referência a um profissional no Regimento Interno, item "Equipe Multiprofissional", o Hospital Universitário não contava, de fato, com nenhum educador de saúde. A exemplo do que ocorre nos hospitais da Prefeitura, esse hospital também não tinha nenhum responsável pela coordenação global das atividades educativas. Além disto, notou-se a inexistência de reuniões periódicas com representantes das diversas categorias profissionais. Sem integração interdisciplinar, é evidente que dificilmente se poderão desenvolver atividades educativas que permitam alcançar os objetivos propostos, sejam eles de caráter genérico ou específico, uma vez que sempre dependerão do consenso e atuação interprofissionais.

Esses casos representam exemplos freqüentes da náo implementação no ntvel institucional. Como se referiu anteriormente, em termos da operacionalização da implementação, se a poltitica de ação não for factivel, também náo sera praticável.

\section{NÍVEL PROGRAMÁTICO}

No estudo já referido dos hospitais da Prefeitura de São Paulo procurou se identificar problemas de implementação não apenas a nível institucional ${ }^{9}$, como discutido acima, mas também a nível programático ${ }^{10}$. Verificou-se estar em desenvolvimento, nos seis hospitais, 51 programas educativos dirigidos a adultos e a crianças.

A Tabela 1 permite observar os grupos profissionais e o pessoal de saúde envolvidos em atividades de planejamento e de execução de programas de ensino. 
tABELA 1 - gRupos envolvidos no PLANEJAMENTO E NO ENSINO de PROGRAMAS DE EDUCAÇÃO EM SEIS HOSPITAIS DA PREFEI TURA dE SÃo PAULO - 1985

\begin{tabular}{|c|c|c|}
\hline \multirow{2}{*}{$\begin{array}{c}\text { GRUPOS PROFISSIONAIS } \\
\text { ENVOLVIDOS }\end{array}$} & \multicolumn{2}{|c|}{ NÚMERO DE HOSPITAIS QUE RELATAM } \\
\hline & PLANEJAMENTO & ENSINO \\
\hline Médicos & 5 & 4 \\
\hline Enfermeiras & 5 & 6 \\
\hline Técnicos de enfermagem & - & 1 \\
\hline Auxiliares de enfermagem & - & 6 \\
\hline Atendentes & - & 4 \\
\hline Dietistas/Nutricionistas & 5 & 6 \\
\hline Assistentes Sociais & 5 & 6 \\
\hline Terapeutas Ocupacionais & 1 & 1 \\
\hline Terapeutas Ap. Respiratórios & 1 & 1 \\
\hline Voluntárias & - & $\mathbf{1}$ \\
\hline Dentistas & - & 1 \\
\hline Psicólogos & 2 & 2 \\
\hline
\end{tabular}

Vários fatores evidenciam problemas referentes ao nível programático nos hospitais estudados - o mais Óbvio é que ambas as colunas (Planejamento / Ensino) deveriam conter sempre a totalidade (número 6) dos seis hospitais observados. No que se refere ao planejamento, surpreende o fato de técnicos, auxiliares de enfermagem e atendentes não estarem envolvidos no processo, por serem esses os que mais freqüentemente interagem com os pacientes. Observe-se que na coluna referente a ensino as auxiliares de enfermagem participam no processo em seis hospitais, enquanto que as atendentes participam apenas em quatro, apesar de nunca terem sido envolvidas nas atividades de planejamento, como seria desejável.

Cabe aqui referir que os programas de educação em saúde devem se fundamentar nos seguintes aspectos: (a) levantamento de necessidades 
educativas do pessoal envolvido nos programas e da população-alvo: (b) delineamento de programas por escrito, aplicação de princípios de ensino $e$ aprendizagem durante a interação com os educadores; (C) documentação e avaliação do componente educativo (conteúdo e processo) e seguimento do processo educativo.

\section{NÍVEL DOS USUÁRIOS}

Do ponto de vista prático, a educação deve fundamentar-se nas necessidades, interesses e problemas dos usuários, já que um dos seus objetivos é a elaboração de programas educativos capazes de proporcionar experiências de aprendizagem que lhes permitam, na prática, aplicar as descobertas da ciência em benefício da sua saúde. ${ }^{6,7,8}$ Apesar disso, raros são os estudos que procuram levantar dados mais cuidadosos sobre os interesses e necessidades da população-alvo. ${ }^{11,12,13,18}$

Estudo por nós realizado em um Hospital do Município de São Paulo coletou perguntas feitas por puérperas internadas em um serviço de obstetrícia, logo após receberem alta médica. ${ }^{7}$ Com isto, procurou-se verificar até que ponto as expectativas haviam sido atendidas no que concerne ao esclarecimento sobre suas próprias condições e sobre as condições de seus filhos. Para tanto elaborou-se a seguinte pergunta: Há alguma coisa que você gostaria de perguntar sobre você ou sobre o nenê (se for o caso) antes de sair do hospital? As respostas foram classificadas em diferentes tópicos, como se apresenta a seguir: saúde da mãe; abortamento, parto, pós-parto, sexologia, planejamento familiar, mortalidade perinatal, crianças sem alta, crianças prematuras, com insuficiência ponderal e com defeitos congênitos, fatores sociais, saúde do nenê, problemas de comunicação, aleitamento e puericultura. Ressalte-se que, em relação a esses tópicos, foram levantados 89 tipos de perguntas de interesse para as puérperas ao deixar o hospital e que, por falta de oportunidade, talvez, jamais foram dirigidas aos médicos, enfermeiras e atendentes de enfermagem e, portanto, respondidas. Entre essas, encontram-se perguntas verdadeiramente dramáticas, tais como: "Por que é que quando fico nervosa desconto nas crianças e bato nelas sem parar? Por que perdi meu filho? Por que abortei duas vezes em seguida? Eu fiz cesária, posso ter mais filhos? Como faço para não ganhar oulro nenê? Do que meu filho morreu?"

Do ponto de vista dos pacientes, um dos aspectos mais importantes do atendimento médico prende-se à comunicação com médicos, enfermeiras e demais pessoal de saúde. MUNFORD e SKIPPER ${ }^{20}$ consideram as falhas no processo de comunicação como uma das mais graves queixas dos pacientes hospitalizados na sociedade ocidental. São duas as razões que levam os pacientes a procurar se comunicar: em primeiro lugar, o desejo de receber informações técnicas (funções instrumentais), em segundo, a necessidade de 
manter contato interpessoal (funções expressivas). Os dois níveis de comunicação são importantes para a saúde do indivíduo. Indivíduos em ambientes estranhos ou experimentando situações novas sentem-se tensos e apreensivos, pois o desconhecido e a incapacidade de controlar situações provocam sensações atemorizantes. Quando se torna impossível controlar fatores negativos, surge, então, a necessidade de conhecer exatamente o que ocorre e de adaptar o comportamento às circunstâncias para diminuir o grau de tensão sentida. Por isso, os pacientes buscam obter informações sobre a natureza e a extensão de um problema ou de um tratamento indicado, sobre o que vai acontecer e em que ocasião e, finalmente, procuram conhecer melhor a infra-estrutura do atendimento médico. Estes exemplos ilustram a problemática relativa ao planejamento a nível dos usuários.

Apresenta-se a seguir, outro exemplo significativo, observado em um Serviço de Obstetrícia em São Paulo. ${ }^{3}$ A dificuldade que os membros da equipe. multiprofissional têm de compreender as características do nível sóciolingüístico dos educandos, dos pontos de vista sociológico e situacional, representa séria barreira na prática da Educação em Saúde. Isto ficou evidente na observação realizada durante uma orientação sobre cuidados com recém-nascidos e outros cuidados. A inadequação do processo educativo refletiu-se claramente nos níveis de fala utilizados, não só durante um processo de demonstração, mas também em palestra proferida para puérperas internadas em uma Enfermaria Obstétrica, sobre tema relativo a cuidados com o recém-nascido, orientação social e nutrição. Enumeram-se aqui algumas palavras ou expressões então utilizadas: aula formal, chance, líquido, retirar no SAME, filiado ao INPS, prevenir, evitar, colaboração, ventilação, agua esterilizada, órgão genital, doador, campanha de sangue, sabão neutro, possibilidade de arriscar, prejudicar, privilegiados, desidratação, improvisação, glicerina, supercaso, RN, produto químico, coincidência, abdómen, assimilar $100 \%$, umbigo mobilizado, retorno, contorno, lembrete, colaborador, flexionar o couro cabeludo, fumaça assimilada, classe média, contaminação, esterilização, entre outros. Tendo em vista o nível sóciocultural dessa população, pode-se afirmar que tais termos ou expressões dificilmente poderiam ser compreendidas pelas puérperas em estudo. Ressalta-se também que parcela considerável delas, apesar de analfabetas, receberam instruções por escrito após a alta médica. Estas considerações ilustram problemas relacionados ao ntvel dos usuários no referido modelo tridimensional.

\section{CONSIDERAÇÕES FINAIS}

Neste artigo procurou-se chamar a atenção das autoridades administrativas para a problemática que, em geral, caracteriza a prática da 
Promoção em Saúde e Educação, particularmente no que diz respeito à operacionalização de programas de saúde pública. Obviamente, os pontos negativos aqui discutidos decorrem da inexistência nas unidades sanitárias de variáveis estruturais, essenciais ao processo educativo nos três níveis abordados. Isto ocorre porque o conhecimento técnico, nessas áreas, $e$ ainda relativamente recente em nosso meio.

É evidente que as mudanças que a leitura atenta destes comentários sugerem quan to à implementação de programas educativos de razoável nível técnico, dependem de uma postura política que pretenda realmente valorizar essa importante dimensão da prática da saúde em cada um dos níveis de intervenção. E justamente isso o que parece não estar ocorrendo, não obstante as frustrações e as necessidades sentidas pelos profissionais da saúde e pelos próprios usuários do sistema da saúde.

A disponibilidade de recursos financeiros encontra-se em crise, não podendo deixar de afetar as atividades educativas, colocadas nesse contexto em plano secundário. Às vezes percebe-se no nível discursivo um tênue ressurgimento de interesse pela área, mas este decorre não do entusiasmo administrativo, político ou político-administrativo, mas de um certo desencanto generalizado em relação à Saúde Pública ou então do próprio público ao confrontar-se com os custos crescentes, e muitas vezes irracionais, de uma prática médica orientada para a doença e não para a saúde.

Espera-se que o modelo organizacional aqui discutido, em suas três dimensões, evite o "much about nothing" dos discursos vazios que às vezes predominam no cenário da administração pública. Estes tendem a proliferar particularmente nos países do terceiro mundo, onde argumentos políticoideológicos provenientes de várias longitudes e latitudes geográficas, nada mais representam senão a tentativa de velar o despreparo técnico que emerge durante a complexa fase de implementação de programas de saúde pública, no que diz respeito a intervenções educativas. De acordo com a definição operacional de implementação, acima referida, a factibilidade precede a implementação. Quer isto dizer que se a política de ação for factível, será também realizável. Nesses termos, sugere-se que indivíduos com poder administrativo de decisão - diretores, chefes de serviço, membros de conselhos deliberativos, entre outros - se empenhem em levar este paradigma organizacional ao contexto das atividades dos serviços de saúde de acordo com as premissas do texto constitucional e com as atuais propostas da cidadania organizada. Ś assim ter-se-á dado o primeiro passo em direcão a um planejamento educativo mais produtivo e eficiente em sintonia com o século XXI. 
CANDEIAS, N. M.F. Health promotion and education planning an integrated approach.

Rev.Esc.Enf.USP, v.30, n.1, p. 149-66, Apr. 1996.

This article addresses the specific problem of Health Promotion an Education planning, which involves three levels in an organization: the institution-wide level, the programmatic level and the user's level. Regardless of where thee technical commitment is indicated, the ideal is to organize at all three levels, otherwise the program planning is likely to be incidental, fragmented, and innefective. Comments are made on the theory of implementation and some barriers to implementation of Health Promotion and Education programs are discussed.

UNITERMS: Planning. Health Promotion and Education programs. Institution level. Programmatic level. User's level. Brazil.

\section{REFERÊNCIAS BIBLIOGRÁFICAS}

1. AMERICAN HOSPITAL ASSOCIATION. Hospital education: survey findings and analyses: 1975. Atlanta, Ga, Bureau of Health Education, Center for Disease Control, 1977.

2. CANDEIAS, N.M.F.; MARCONDES, R.S. Diagnóstico em educação em saúde: um modelo para analisar as relações entre atitudes e práticas na área da saúde. Rev. Saúde públ. v. 13, n.2, p.63-8, 1979.

3. CANDEIAS, N.M.F. Educação em saúde na prevenção do risco gravídico pré-natal e interconcepcional. São Paulo, 1979. Tese (Doutorado) - Faculdade de Saúde Pública, Universidade de São Paulo.

4. CANDEIAS, N.M.F. Fumo durante a gestação: aspectos negativos de um problema comportamental. Rev. Saúde públ., v.13, n.3, p.244-63. 1979.

5. CANDEIAS, N.M.F. Assistência pré-natal: conhecimentos, atitudes e práticas de mulheres internadas no Serviço de Obstetrícia de um Hospital do Município de São Paulo, Brasil. Rev. Saúde públ., v. 14, n.4, p.427-38, 1980

6. CANDEIAS, N.M.F.; MARCONDES, R.S. Identifying educational needs of school children in a secondary school in Såo Paulo, Int.J. Health Education, v.23, p.42-8, 1980.

7. CANDEIAS, N.M.F. Necessidades educativas de puérperas com alta médica. Rev. Bras. Enf., v. 34, n.2, p. 146-52, 1981.

8. CANDEIAS, N.M.F. Ensino de saúde: interesses na área de saúde de escolares adolescentes. Cad. Pesq., v.50, p.40-52, 1984

9. CANDEIAS, N.M.F. Educação de pacientes nos hospitais da Prefeitura de São Paulo - nível institucional. Rev. Paul. Hosp., v. 34, n.4-5-6, p.55-9, 1986.

10. CANDEIAS, N.M.F. Educação de pacientes nos hospitais da Prefeitura de São Paulo - nível programático. Rev. Paul. Hosp., v.34, n. 7-8-9. p.122-33, 1986.

Rev.Esc.Enf.USP, v.30, n.1, p.149-66, abr. 1996. 
11. CANDEIAS, N.M.F. et al. Delineamento do papel dos especialistas em educaçăo em saúde, uma proposta técnica. Rev. Saúde publ., v.25, n.4, p.289-98, 1991.

12. CANDEIAS, N.M.F. Evaluating the quality of health education programmes, some comments on methods and implementation. Hygie, v. 10, p.40-4, 1991.

13. CANDEIAS, N.M.F. Workers' risk perception in Brazil, a challenge for health promotion and education planning. Promotion Ed., v.1, n.1, p.11-7, 1994

14. CARVALHO, G.I de; SANTOS, L. Sistema único de saúde. Comentários à Lei Orgânica da Saúde (Lei 8.080/90 e Lei 8.142/90). São Paulo, HUCITEC, 1992.

15. DEEDS, S.G. et al. A model for patient education programming. Chicago, Public Health Education, American Public Health Association, 1979.

16. FARIA, M.M; JATENE, A. Saúde e Movimentos Sociais, São Paulo, EDUSP, 1995

17. HEIMANN, L.S. et al. O Município e a saúde, São Paulo, HUCITEC, 1992.

18. JEUKENS, M.M.F. Conhecimentos de homens infectados pelo HIV sobre procedimentos de autocuidado. São Paulo, 1992. Dissertação (Mestrado) - Escola de Enfermagem. Universidade de São Paulo

19. JUNQUEIRA, L.A.P.; INOJOSA, R.M. Descentralização do modelo de prestação de serviços de saúde em São Paulo, Rev. Adm públ., v.24, n.4, p.7.25, 1990.

20. MUNFORD. E.; SKIPPER Jr., J.K. Sociology in hospital care. New York, Harper and Row, 1967.

21. OTTOSON, J; GREEN, L. Reconciling concept and context: theory of implementation. Adv. Health Ed. Promotion, v.2, p.353-382, 1987. 